\title{
Cultura, História e Serviço Social: entrevista com Suely Gomes Costa*
}

\author{
Carla Cristina Lima de Almeida* \\ Ana Lole**
}

\begin{abstract}
Entrevista realizada com Suely Gomes Costa, assistente social e economista, professora titular (aposentada) da Escola de Serviço Social na Universidade Federal Fluminense (UFF). Professora associada do Programa de Estudos Pós-Graduados em Política Social e do Programa de Pós-Graduação em História, ambos na UFF. Autora de vastíssima produção intelectual na área do Serviço Social e Feminismo. Esteve presente nos debates da profissão no período do Movimento de Reconceituação, com participação na elaboração do Documento de Teresópolis. Seu livro Signos em Transformação: a dialética de uma cultura profissional, publicado pela Editora Cortez em 1995, conta-nos a história do Serviço Social pelo viés da cultura enquanto um processo de longa duração. A entrevista, que ora é publicada, mostra muitos cruzamentos - a história, a luta feminista, o Serviço Social - que envolvem um diálogo intenso com autores afeitos a um fazer históricopolítico marcado pela experiência e pelo exame dos processos sociais.

Nada mais importante em tempos atuais.
\end{abstract}

\footnotetext{
* Entrevista realizada por escrito, via e-mail, em julho de 2016.

** Membro do Comitê Editorial da Revista Em Pauta e professora associada da Faculdade de Serviço Social/UERJ. Correspondência: Universidade do Estado do Rio de Janeiro - Faculdade de Serviço Social. Rua São Francisco Xavier, 524, 8andar, Bloco D, sl. 8017 - Maracanã, Rio de Janeiro/RJ - Brasil. CEP: 20550-900. Email: <analole@gmail.com>.

*** Doutora em Serviço Social pela PUC-Rio e professora do Departamento de Serviço Social de Niterói na ESS/UFF. Correspondência: Universidade Federal Fluminense - Departamento de Serviço Social de Niterói. Rua Prof. Marcos Waldemar de Freitas Reis, BI. E, Campus Universitário do Gragoatá - São Domingos - Niterói/RJ - Brasil. CEP: $24210-$ 201.Email:<analole@gmail.com>.
} 
Você tem os historiadores Thompson e Hobsbawm como interlocutores mais próximos. Como esses intelectuais contribuíram e contribuem para o debate de cultura e classes sociais, considerando o debate de Hobsbawm sobre a "invenção das tradições"?

Thompson e Hobsbawm tem uma forte inflexão "antropológica" no exame da experiência humana. E isso, para mim, os tornam bem mais próximos dos processos sociais que examinam. Eles rompem com abordagens marcadas por grandes generalizações conceituais sobre o mundo social, essas que escondem muito da vida social. E isso muda muito os resultados do exame das fontes históricas.

Em seu livro "Signos em Transformação: a dialética de uma cultura profissional" você recupera a história do Serviço Social por ângulos originais, inspirada na teoria de Thompson: "a cultura profissional"; "perspectiva de longa duração histórica"; "o cotidiano e as ações dos sujeitos históricos". Fale-nos um pouco desse "fazer historiográfico" e sua importância para a profissão.

A perspectiva da longa duração histórica nos permite colocar em cena as muitas temporalidades de um lugar, e também, nelas, a variação de usos e costumes, lembrando que há continuidades e rupturas de modos de ser e de viver. Essa perspectiva que é teórico-metodológica torna menos insegura a formulação de conceitos sobre usos e costumes. Distinguem-se aí também continuidades e rupturas de práticas sociais: há as que permanecem e há as que mudam. Captura-se - com menos enganos/erros - a dinâmica social de um dado tempo. No caso do Serviço Social, essa perspectiva permite distinguir - com mais segurança - a transformação das práticas sociais e de seus significados em relação às formas de atender um conjunto de necessidades humanas. Também no caso, implica em reconhecer as desigualdades inerentes às relações de gênero diante de complexas mudanças civilizatórias conduzidas por homens e mulheres. Há conceitos que mudam rapidamente e há os que também permanecem; tudo isso ao mesmo tempo. Essa complexa configuração, se desvendada em alguns que sejam seus sentidos civilizadores, tanto nos permitem distinguir muito de uma dada dinâmica social, como do rumo de ações na busca da felicidade. Ela coloca em cena usos e costumes e possíveis motivações que mantêm continuidades e engendram mudanças de práticas sociais. E para quem trabalha com história cultural, isso é mais que fundamental...

Nos estudos de Thompson sobre a classe operária inglesa, tem sido observada a ausência da condição de gênero desses sujeitos. Entretanto, Scott (1992) considera a obra de Thompson uma espécie de "pré-condição do discurso feminista socialista". Como você vê as contendas entre os estudos feministas e o marxismo e, também, a contribuição de Thompson para este debate? 
Thompson - por tradição marxista - é um pesquisador atento aos movimentos de homens e mulheres dos lugares e tempos que pesquisa. Assim, no exame das experiências de que se ocupa, ele nunca perde de vista as relações capital/trabalho. Apenas, não as simplifica... As contendas feministas com a clássica abordagem marxista decorrem, sobretudo, de uma equivocada - a meu ver - leitura de Marx. Há uma enorme simplificação histórica da complexa dinâmica social. Os feminismos surgem fazendo rupturas com usos e costumes ancestrais de confinamento feminino ao lugar dos cuidados da casa e da prole. A ruptura com uma dada construção do que "deve" ser masculino e ser feminino dependeu de muitas lutas, daí as origens dos muitos feminismos. As mulheres se reconheceram como pessoas impedidas de valerem tanto quantos os homens, de terem uma humanidade comum... E sobre esse assunto, vocês conhecem tanto quanto eu... No cerne da questão, está o debate sobre a igualdade humana...

Em seu artigo "Proteção social, maternidade transferida e lutas pela saúde reprodutiva", publicado em 2002, você cunhou o conceito de "maternidade transferida" com enorme presença nos estudos feministas e de gênero na atualidade, apontando para diferenças de classe, raça e gênero na construção do sujeito mulher. Você poderia nos contar sobre o contexto de elaboração desse conceito e avaliar sua repercussão?

A minha formação em história é marcada pela rica convivência com a Profa. Eulália Maria Lahmeyer Lobo, minha professora e orientadora de mestrado, também marxista, e depois, no doutorado, sob orientação da Profa. Dra. Rachel Soihet, essa do "ramo". Aprendi com ambas que história se faz com exame da experiência social de um dado tempo e lugar. Nessa minha formação, pude distinguir os muitos tempos e lugares dos vários brasis, desde a experiência colonial. Foi uma longa "viagem"... Defronteime - de cara - com o processo de formulação de conceitos. No caso da história, aprendi com ambas e tantos outros/as professores/as que eles emergem exclusivamente da experiência histórica: são datados e localizados. Bem, na minha trajetória, na virada dos anos 1970/1980, eu me tornara feminista. E, nessa condição, pude por experiência, perceber, com muita nitidez, na história brasileira, uma regularidade histórica de longa duração: o papel central das amas nos cuidados das proles de seus senhores/ as - inclusive, na amamentação. Eu não teria esse insight se não estudasse o Brasil colônia. Reconheci, nessa importante tradição, uma forma de convivência social que ainda hoje persiste transformada no emprego doméstico, sempre pelas mesmas razões: a maior/menor liberdade de saída das muIheres de todas as camadas da população para outros espaços que não os seus próximos/íntimos. Essa saída - fosse qual fosse a classe social dependia - em grande parte - da oferta de cuidadoras de suas, então, proles.

Mas também eu vivi isso na minha própria existência e de minha família: somos 8 irmãos e vivemos - por muito tempo - no interior do Brasil, em 
novas fronteiras abertas, por onde meu pai circulou como médico... Do Rio onde estudara, foi pra Londrina (PR) onde morava sua família. Depois, o destino foi Mato Grosso: primeiro, Três Lagoas e depois Corumbá e Cuiabá. A seguir, Niterói. E, em todos esses lugares, tínhamos ramos familiares. Nos anos 1940/1950 do século passado, meu pai dizia, em tom de blague, que minha mãe era "mandatária de vários ministérios" e os enumerava: o da lavandaria, o da copa/cozinha; o da arrumação e o dos cuidados com a prole. Mamãe também costurava/bordava para todos os filhos... Adorava! Mas ela também olhava em volta e vivia as dificuldades das mulheres que a apoiavam: eram todas dependentes de mais mulheres... Essa percepção emerge da minha própria história de vida. Ela ganhará, assim, uma dimensão conceitual. Daí, creio, ter sido o conceito formulado: percebi que ele correspondia a uma regularidade histórica de longa duração. Pude desnaturalizar, penso eu, um dado costume de longa duração histórica e desvendar algumas de suas peculiaridades: para que algumas mulheres ganhassem autonomia em relação aos afazeres domésticos ou aos deslocamentos para espaços fora de suas casas - fosse em atividade privada, fosse pública - era preciso que uma enorme quantidade de outras mulheres trabalhassem para elas, fosse mediante pagamento ou favores e, sempre no espaço doméstico, num outro que não o de suas casas... Esse tipo de trabalho doméstico se assenta, também claramente, no estatuto da nossa experiência escravista. Ela ajudou muito nessa "transição" das atividades domésticas femininas "de dentro" e "de fora", próprias ao mundo das casas. E isso definiria também um padrão comportamental que implicava numa relação de confiança por se tratar de decisão de "transferir a maternidade". Essa prática foi extremamente necessária ao deslocamento das mulheres para o mundo do trabalho e seu assalariamento. E isso persiste entre nós e em muitas partes do mundo ainda hoje! Claro que obtendo também conquistas trabalhistas.

Você tem sublinhado, ao longo de seus trabalhos, a necessidade de incorporar a experiência das mulheres nas análises dos Sistemas de Proteção Social. Que contribuições esse ponto de vista pode trazer para a produção do conhecimento?

Muitas! A igualdade de homens e mulheres e entre mulheres é um direito mais que reconhecido em todas as sociedades contemporâneas. A busca dessa igualdade se tornará um imperativo civilizatório. Mas isso tem mudado conforme a cultura de muitas regiões do planeta e de modo muito desigual. Embora as mulheres tenham chegado a muitos espaços da atividade humana, o peso das tradições culturais ainda emperra as lutas por plena igualdade... E isso é observável no nosso dia-a-dia.

No Brasil, a militância feminista dos anos 1970 e 1980 é considerada um marco para a história das batalhas pelos direitos das mulheres. Você participou ativamente desse cenário no campo da saúde. Conte-nos sobre sua 
experiência e como você avalia as lutas sociais contemporâneas (manifestações de 2013; pró e contra impeachment da presidenta Dilma) bem como a participação dos movimentos feministas e suas formas de luta, como "Marcha das Margaridas", "Marcha das Vadias" entre outras?

Sim, eu fui bastante ativa nas lutas desse período, sobretudo, por direitos reprodutivos. À época, eu orientava alunos/as em estágio no Centro de Saúde Santa Rosa, em Niterói, como Professora da Escola de Serviço Social na UFF, nessa área. E nesse caminho, muito movida pelas causas em que o gabinete da Dep. Lucia Arruda na ALERJ (Assembleia Legislativa do Estado do Rio de Janeiro), se empenhava como condutor do movimento feminista que ia se organizando através desse seu mandato, vi-me entusiasmada pelas causas desse momento e me associei às lutas feministas que aí se expandiam. E isso porque também ia descobrindo que os movimentos feministas haviam chegado a esse período muito fracionados e com muitas disputas e dissenções internas. Nós, mulheres, experimentamos, entre nós, muitas desigualdades: por nível de renda e de instrução, por cor de pele, por tradições de convivência de classes que nos apartam enfim... por razões próprias ao processo civilizador que temos construído. Visto isso, pude concluir que não adiantava alimentar utopias genéricas... Sempre preferi o lugar de trabaIho que juntasse vida pessoal e profissional. Acho que foi assim que pude sentir mais de perto a relevância de atuar e de contribuir no meu espaço profissional com a efetividade das lutas por conquista de direitos. No caso da saúde, nessa experiência do Centro de Saúde, dediquei-me às questões dos direitos reprodutivos e aprendi muito. Foi um trabalho coletivo de muita fertilidade! Hoje, acompanho os movimentos à distância. Aqui ou ali, faço uma intervenção, como esta, contribuindo com reflexões e debates ao meu alcance. Não estou mais filiada a nenhum movimento, em especial. Também sinto que é preciso reconhecer a hora de fazer-se substituir... Os feminismos são geracionais... Isso também eu aprendi. Aprendi que novas questões renovam os movimentos e exigem sempre novas energias para a fermentação de mais lutas por igualdade. Acho que é isso que me cabe registrar.

Obrigada pela oportunidade de repensar trajetórias. Elas são sempre geracionais... Elas se renovam nesse movimento... Obrigada pela chance dessa reflexão!

\footnotetext{
1 "Lucia Arruda, fotógrafa, foi a primeira mulher a se declarar feminista na tribuna da ALERJ. Foi eleita aos 26 anos de idade entrando para a história política como a primeira deputada estadual eleita pelo PT (Partido dos Trabalhadores). No final dos anos [19]70, início dos anos [19]80 passou a integrar o movimento pela anistia e o núcleo do Brasil Mulher e, depois, a Comissão de Mulheres do PT. Foi uma das deputadas que mais dedicou seu mandato à causa feminista. [...] Coube ao gabinete de Lúcia Arruda um papel fundamental, entre outros, na criação da Delegacia das Mulheres no Estado do Rio de Janeiro. No final do primeiro mandato a deputada criou a Comissão Especial de Saúde e Direitos Reprodutivos". (MOREIRA \& ARAÚJO, 2010, p. 30).
} 


\section{Referências}

COSTA, Suely Gomes. Movimentos feministas, feminismos. Estudos Feministas, Florianópolis, v. 12, N. E., p. 23-36, set./dez. 2004.

. Proteção Social, maternidade transferida e lutas pela saúde reprodutiva. Estudos Feministas, Florianópolis, v. 10, n. 2, p. 301-324, jul./dez. 2002.

. Signos em Transformação: a dialética de uma cultura profissional. São Paulo: Cortez, 1995.

HOBSBAWM, Eric; RANGER, Terence (orgs.). A invenção das tradições. Rio de Janeiro: Paz e Terra, 1984.

MOREIRA, Lourdes; ARAÚJO, Hildete Pereira de Melo Hermes de. Feminismo na Assembleia Legislativa do Rio de Janeiro: as deputadas feministas e a promoção de políticas para mulheres. Londrina, Universidade Estadual de Londrina, 24 e 25 de junho de 2010. Anais...

SCOTT, Joan W. História das Mulheres. In: BURKE, P. (org.). A escrita da História. Novas perspectivas. São Paulo: Unesp, 1992.

THOMPSON, Edward P. A formação da classe operária inglesa. 3 volumes. Rio de Janeiro: Paz e Terra, 1987.

DOI: $10.12957 /$ rep.2016.27870

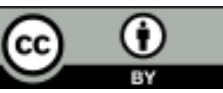

A Revista Em Pauta: Teoria Social e Realidade Contemporânea está licenciada com uma Licença Creative Commons Atribuição 4.0 Internacional. 